\title{
Constructability and Economical Comparison Between Two Proposed Permanent Shoring Systems in Qatar: A Case Study
}

\author{
Mohammed Alfarra \\ mohammed.alfarra@seeroeng.com \\ Seero Engineering Consulting, Doha, Qatar \\ Mohammed Sadeq \\ mohammed.sadeq@seeroeng.com \\ Seero Engineering Consulting, Doha, Qatar \\ Husam Sadek \\ hsadek1@1su.edu \\ Louisiana State University, Baton Rouge, Louisiana, USA
}

\begin{abstract}
This paper introduces the constructability and economic feasibility study of using one of the proposed two types of permanent shoring system for a highway project in Qatar. The cast-in-situ cantilever retaining wall and the contiguous piles wall were suggested and designed to be used as a permanent retaining system at a multi-level intersection. In this study, the construction complexities of using the cantilever retaining wall system are illustrated and compared to the contiguous piles wall. Besides, the impact on the Right-of-Way (ROW) of the road, excavation process, traffic circulation, and existing utilities are discussed. The paper summarizes the difference in the required construction materials and excavation quantity for the proposed shoring systems at the same retained elevation. Furthermore, the design of both systems is performed based on the local and international guidelines and regulations of the shoring system design in Qatar. The study has shown that both suggested systems are providing the same finishing quality while the contiguous piles system is more effective in minimizing economic and site preparation challenges. It also provides safer utilities handling and faster construction sequencing without cost increases.
\end{abstract}

Keywords: Shoring system; Contiguous pile wall; Cantilever retaining wall; Qatar

\section{INTRODUCTION}

Qatar is witnessing a significant upgrade in the infrastructure and transport systems, especially in highways and multi-grade intersections. These multi-grade intersections are usually supported by retaining structures that come as a part of the contractor's role to construct within the limited Right of Way (ROW). Retaining structures are commonly used to retain soil, rock, or water and to withstand their lateral pressures. Using these walls supports roads at different levels, accommodates extra lanes for the roads, and stabilizes slopes. There are various types of retaining wall structures that are used for different objectives, such as; gravity, cantilever, counterfort, piled, sheet pile, anchored, and Mechanically Stabilized Earth (MSE) retaining walls (Standard Specification for highway bridges, 2002).

In the planning stage of any project, the selection of the optimum retaining wall system is not an easy task since it depends on many limitations as safety, economy, 
constructability, right of way, underground utilities, and stability.

In this paper, two permanent shoring options were proposed, designed, and compared for a multi-grade intersection project in Qatar. The difference in the level is $10 \mathrm{~m}$ between the ground level and a bypass road. The project is located in a fully developed area in Doha city, which added some complexity in choosing the most suitable retaining wall system. The proposed retaining system is very close to the Right of Way (ROW), and existing utilities are crossing the proposed location of the shoring system. The main contractor of the project was recommended to substitute the cantilever retaining wall system with a contiguous piles wall system. Since the proposed retaining structures will be fabricated and cast in the site, more challenges are expected during the construction process. The objective of this paper is to discuss the constructability and economic aspects of both systems. Their effects on the ROW and existing utilities are evaluated to adopt the most feasible option.

\section{GEOTECHNICAL PARAMETERS AND SITE CONDITION}

The geotechnical investigation of the project site was reviewed to determine the soil properties. Furthermore, the topographical survey, geometric layouts, and excavation levels were used to identify the final retaining systems' lengths and the height of piers on top of the cap beam. It is worth mentioning that the whole shoring system length is within the Quaternary Deposit (QD) and Simsima Limestone (SL) layers. The design ground profile and the geotechnical parameters provided in the geotechnical investigation report are summarized in Table 1.

Table 1: Design ground profile and geotechnical parameters

\begin{tabular}{|c|c|c|c|c|c|c|c|}
\hline \multirow{2}{*}{$\begin{array}{c}\text { Layer } \\
\text { Lithology }\end{array}$} & \multicolumn{2}{|c|}{ Depth [m] } & \multirow{2}{*}{$\begin{array}{c}\text { Specific Gravity } \\
(\mathbf{\gamma})\left[\mathbf{k N} / \mathbf{m}^{3}\right]\end{array}$} & $\begin{array}{c}\text { Internal angle of } \\
\text { friction }(\boldsymbol{\phi})[\mathbf{d e g}]\end{array}$ & $\begin{array}{c}\text { Cohesion of } \\
\text { Soil } \\
(\mathbf{C})[\mathbf{k P a}]\end{array}$ & $\begin{array}{c}\text { Module of } \\
\text { Elasticity } \\
\mathbf{( E )}[\mathbf{M P a}]\end{array}$ & $\begin{array}{c}\text { Poisson's } \\
\text { ratio } \\
(\mathbf{v})\end{array}$ \\
\hline From & To & & 18.0 & 35.0 & 0.0 & 25.0 & 0.2 \\
\hline SL & 0.00 & 0.80 & 25.0 & 45.0 & 190.0 & $2,600.0$ & 0.3 \\
\hline
\end{tabular}

Although the geotechnical investigation report mentioned that the groundwater table level is not at the level of the piles wall, it was assumed that the level of the groundwater table is one meter below excavation levels for conservative considerations. Besides, based on the local guidelines, it has been assumed that the controlled backfill will have the properties presented in Table 2 (Interim Advice Note No. 009, Revision No. A2, 2016).

Table 2: Geo-mechanical parameters of backfill and subgrade material

\begin{tabular}{|c|c|c|c|c|}
\hline Layer Lithology & $\begin{array}{c}\text { Specific Gravity }(\mathbf{y}) \\
{\left[\mathbf{k N} / \mathbf{m}^{\mathbf{3}}\right]}\end{array}$ & $\begin{array}{c}\text { Internal angle of } \\
\text { friction }(\boldsymbol{\phi})[\mathbf{d e g}]\end{array}$ & $\begin{array}{c}\text { Cohesion of Soil } \\
(\mathbf{C})[\mathbf{k P a}]\end{array}$ & $\begin{array}{c}\text { Module of Elasticity } \\
(\mathbf{E})[\mathrm{MPa}]\end{array}$ \\
\hline Backfill \& Subgrade Material & 20.0 & 35.0 & 0.0 & 40.0 \\
\hline
\end{tabular}

On the other hand, the conditions of the project site are very complicated due to the underground utilities, including electrical high voltage cables, which are crossing the location of the shoring system at the intersection. Moreover, the proposed retaining walls are very close to the ROW, and that affects the traffic flow and the excavation process. 
Figure 1 describes the approximate shape for each system considering the right of way and existing utilities location. It is obvious that the excavation limit of the cantilever retaining wall exceeds the ROW and influences the traffic circulation. However, proposed contiguous piles wall system provides more flexibility in the excavation stage and maintains a comfortable distance to ROW, which does not affect the existing utilities or traffic plan.

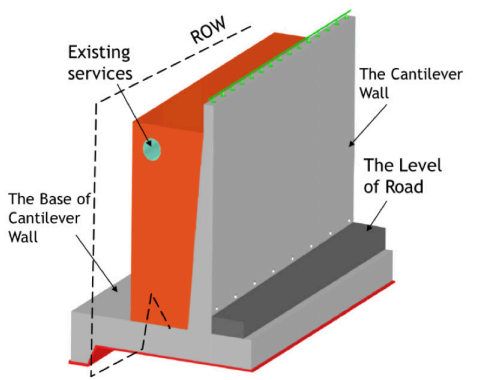

(a) Cantilever Retaining Wall System

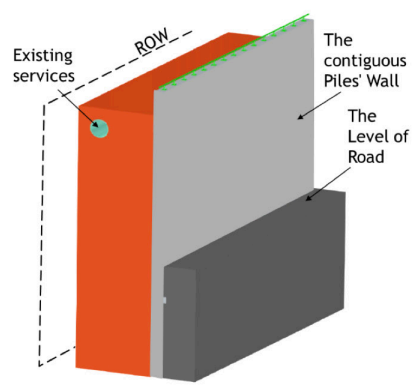

(b) Contiguous Piles Wall System

Figure 1: The excavation and utilities challenges for both proposed permanent shoring systems

\section{COMPARISON BETWEEN TWO PROPOSED SHORING SYSTEMS}

Two options of retaining systems are assessed from an economic and constructability perspective to select the most effective retaining structure that can be built rapidly while offering a safe and long-lasting solution. In this project, the proposed systems have been designed using the same assumptions and criteria following the local and international codes (Interim Advice Note No. 009, Revision No. A2, 2016; BS5400, 1990). At the end of the construction stage, the suggested two systems should have the same finishing quality.

\subsection{Effect of the Retaining System Type on the Right of Way (ROW) and traffic flow}

The retaining walls are usually designed to hold consolidated and unconsolidated soil or water with different levels near to roads and highways. Hence, it is essential to select the ease construction and safer system to avoid any risks or disruption on the traffic plan. As shown in Figure 1, the base of the cantilever retaining system is too wide and overlaps with the ROW. As a result, the equipment used for the excavation process will impact the flow of the traffic. Moreover, Temporary Traffic Management (TTM) plans will be required to avoid any obstruction, risk, or delay on the vehicles or pedestrian movements. On the other hand, the contiguous piles wall system requires limited space for construction compared to the cantilever retaining wall system, which minimizes the interaction with the traffic flow.

\subsection{Effect of the Retaining System Type on the quantities of construction materials and cost}

As the proposed permanent shoring system will be constructed on four approaches of the multi-grade intersection with an approximate length of $1.7 \mathrm{~km}$, the cost is an 
essential factor in adopting the optimum type of the retaining systems. Besides, both retaining walls are designed using the reinforcement concrete and steel rebars available in Qatar. The final cross-sectional of the cantilever retaining wall is presented in Figure 2 , while Figure 3 shows the final dimensions of the contiguous piles wall system based on the approved design by the relevant authorities and after carrying out all the required design checks.

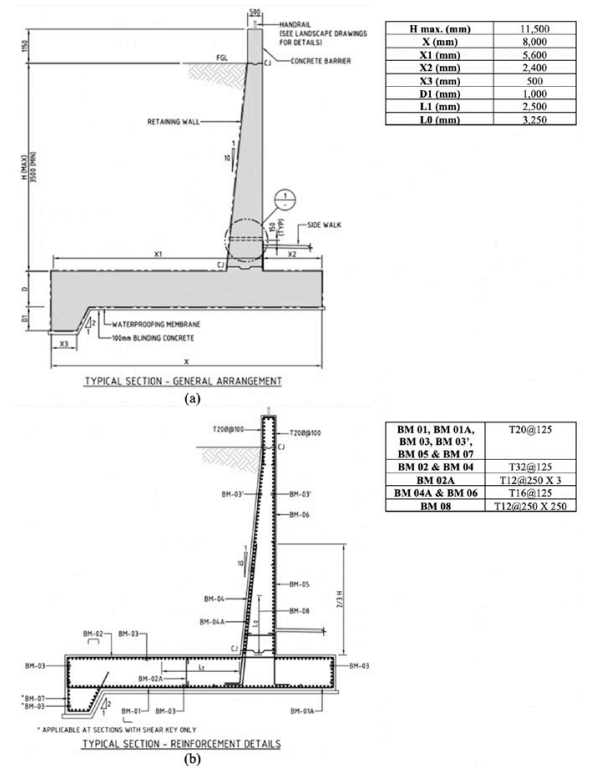

Figure 2: The proposed cross-sectional of the cantilever retaining wall system

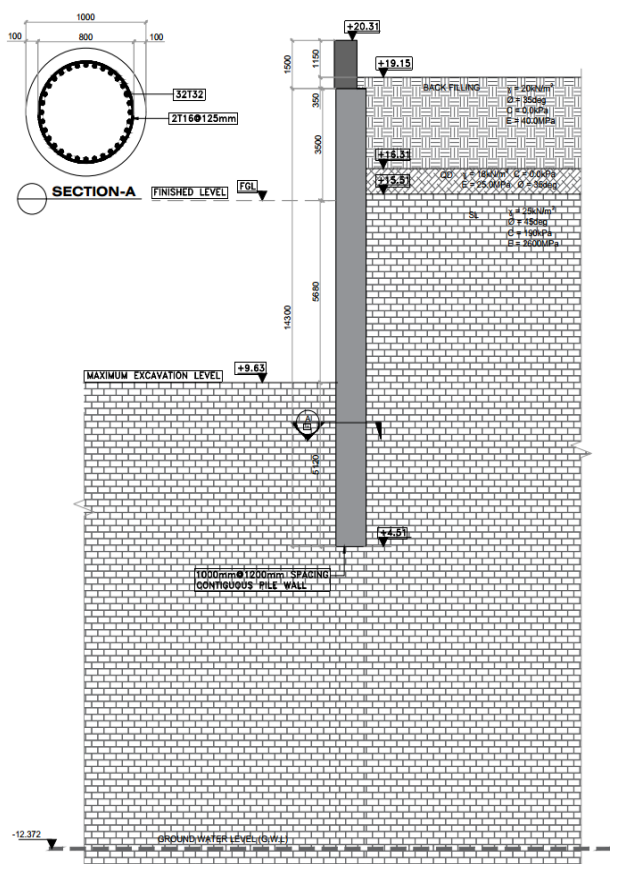

Figure 3: The proposed cross-sectional of the contiguous piles wall system 
Based on the cross-section of the proposed permanent shoring systems, the required construction material and excavation quantity of the two options for the same retaining height (level) are presented in Table 3.

Table 3: The required construction materials for both options

\begin{tabular}{|c|c|c|c|}
\hline Item & Reinforcement Steel (kg/m) & Concrete (m $\mathbf{3} / \mathbf{m})$ & Excavation Quantity (m $\mathbf{3} / \mathbf{m})$ \\
\hline Cantilever Wall & 3056 & 26 & 99 \\
\hline Piles Wall & 3718 & 13 & 9 \\
\hline
\end{tabular}

In addition to the fact that the contiguous piles wall system provides an effective solution to avoid clashes with the underground utilities during the excavation stage and maintain the traffic flow and timeframe without any delays, it also reduces the material and construction cost dramatically.

As shown in Table 3, the proposed contiguous piles retaining system minimizes the quantity of the required concrete to the half, while it almost requires a similar quantity of the steel rebars for the cantilever retaining wall. On contrast, the contiguous piles system decreases the excavation quantity by about $90 \%$ compared to the other option due to the excavation methodology. Vertical drilling is used for contiguous piles system, while a deep rectangular area must be excavated for the base of the cantilever retaining wall as shown in Figure 1a. Accordingly, the required construction cost will be noticeably dropped when the contiguous piles system is used as a permanent system in such site conditions.

\subsection{Effect of the Retaining System Type on the underground utilities}

Great attention is usually paid to the relocation of existing underground utilities and excavation phase of any project site, especially when it has chemicals, flammable materials, or high voltage electrical cables. As part of the constructability evaluation of the proposed system, it was found that using the cantilever retaining wall system might be difficult due to the existing underground utilities, which include high voltage electrical cables and pipelines. These utilities must be relocated into another path that may lead to disruption of service to residential areas surrounding the project. The proposed contiguous piles wall system offers a better solution, by having the piles constructed away from the crossing underground utilities. Furthermore, no influences on the accessibility of domestic services should occur.

\subsection{Effect of the Retaining System Type on the project timeframe}

Due to the continuous development of the roads, highways, and infrastructure networks in Qatar, most of the planned and ongoing projects must be completed following the Qatar National Vision 2030. In addition, the construction companies are always implementing proper scheduling for the construction activities of their projects. Thus, adopting the ease of construction retaining system is necessary to comply with the timeframe of the execution plan. As a result of the effects of the cantilever retaining wall system on the ROW and the existing underground utilities, it seems that this option should be avoided to complete the construction within a reasonable timeframe. Accordingly, using the 
contiguous piles wall system provides more flexibility in the excavation process, which means more time and effort will be saved.

\section{CONCLUSION AND RECOMMENDATIONS}

This paper evaluated and compared the constructability and economic aspects for two proposed retaining systems to adopt the most effective option as a permanent shoring system. The cantilever retaining wall and piles retaining wall systems have been evaluated in terms of their impacts on the construction process and the required quantities. The selection of one of the suggested systems was not an easy task due to the complicated site conditions.

Based on the comparison of this study, it can be concluded that using the contiguous piles retaining wall system as a shoring system of multi-grade highway intersection is more economical than the cantilever retaining wall. Furthermore, the contiguous piles wall system shows effectiveness in the construction process, timeframe, handling utilities, and excavation procedure.

On the other hand, the selection of the contiguous retaining wall system reduces the quantities of the overall materials needed for the construction, which directly impacts the project budget and cost.

\section{REFERENCES}

BS5400: Steel, concrete and composite bridges (1990). British Standards Institution. Interim Advice Note No. 009, Revision No. A2 (2016). Public Work Authorities (Ashghal).

Standard Specification for highway bridges (2002). American Association of State Highway and Transportation Officials (AASHTO). Washington D.C, the USA. 